\title{
Study on increasing the solubility and dissolution rate of sulfamethoxazole by cyclodextrins
}

\begin{abstract}
The aim of this study was to enhance the solubility and the dissolution rate of sulfamethoxazole (SMZ) by preparing the inclusion complexes with $\beta$-cyclodextrin $(\beta$ $\mathrm{CD})$, hydroxypropyl- $\beta$-cyclodextrin $(\mathrm{HP} \beta-\mathrm{CD})$, and $\gamma$-cyclodextrin $(\gamma-\mathrm{CD})$. Selection of an appropriate complexing agent and the method of formulation are critical. The effect of the type of cyclodextrins used for the preparation of complexes, on the in vitro dissolution profiles and solubilities in different mediums ( $\mathrm{pH} 4.5$ and $\mathrm{pH} 7.0)$ was also evaluated. The interaction between SMZ and cyclodextrins in solution was studied by the phase-solubility method. Inclusion complexation was confirmed by the results from the studies of infrared spectoroscopy (IR) and differential scanning calorimetry (DSC). The effect of watersoluble polymers i.e., polyethylene glycols 4000, 10000, 20000 and non-ionic surfactants i.e., polysorbate 20,40,60 on the complexation of SMZ with $\mathrm{CD}$ were also investigated by the same methods. The rates of release of the active material from the complexes were determined from dissolution studies using USP XXII paddle method. As a result of this study, it was found that the solubility of SMZ was significantly enhanced by inclusion of $\beta$-CD especially when the water soluble additives are added (from $0.086 \mathrm{mg} \mathrm{mL}^{-1}$ to $0.377 \mathrm{mg} \mathrm{mL}^{-1}$ with SMZ: $\left.\beta-C D: P E G 20000\right)$. Thus, it was thought that the bioavailability of SMZ could be increased.
\end{abstract}

Keywords: cyclodextrins, sulfamethoxazole, solubility, dissolution rate
Volume 7 Issue 4 - 2018

\author{
Jülide Șahin, Nurten Özdemir \\ Department of Pharmaceutical Technology, Ankara University, \\ Turkey
}

Correspondence: Nurten Özdemir, Ankara University, Faculty of Pharmacy, Department of Pharmaceutical Technology, 06100 Tandoğan-Ankara, Turkey, Fax + 90312213108I, Tel + 903122033151, Email nozdemir@pharmacy.ankara.edu.tr

Received: May 24, 2018 | Published: July 24, 2018

\section{Introduction}

Sulfonamides are bacteriostatic agents which are systematically used in the treatment of bacterial infections. SMZ, a derivative of sulfonamide, inhibits the synthesis of folic acid, which is an important metabolite of bacteria's DNA synthesis. ${ }^{1,2} \mathrm{SMZ}$ is absorbed from gastro-intestinal area; however, its absorption and bioavailability are limited with its dissolution rate, due to its low solubility like all the other sulfonamide groups. The aim of the study was to prepare the inclusion complexes of SMZ using $\mathrm{CD}_{\mathrm{s}}$ to enhance the solubility, dissolution rate and oral bioavailability.

When poor bioavailability is due to low solubility, CDs are of extreme value. Preconditions for the absorption of an orally administered drug are its release from the formulation in dissolved form. When drug is complexed with $\mathrm{CD}$, dissolution rate and, consequently, absorptionare enhanced. ${ }^{3} \mathrm{CDs}$ have been used as an excipient to transport the drugs through an aqueous medium to the lipophillic absorption surface in the gastrointestinal tract, i.e., complexation with CDs has been used to enhance the dissolution rate of poorly water-soluble drugs. ${ }^{4}$

$\mathrm{CD}_{\mathrm{s}}$ which are made up of $6 \mathrm{D}(+)$ glucopyranose units at minimum, with $\alpha$ 1-4 glycoside bonds and formed as a result of degradation of starch by the help of glucosyltransferase (CGT) enzyme, are cyclic oligosaccharides with hydrophobic cavity and hydrophilic outer surface. ${ }^{5} \mathrm{CD}_{\mathrm{s}}$ can be defined as enzymatically modified starch made of glucopyranose units. ${ }^{6}$ The commonly available $\mathrm{CD}_{\mathrm{s}}$ are $\alpha-, \beta$ - and $\gamma$-cyclodextrins, which consist of six, seven and eight glycopyranose units, respectively. ${ }^{7,8}$ The more glucose units there are, the bigger dimensions $\mathrm{CD}_{\mathrm{s}}$ have. $\mathrm{CD}_{\mathrm{s}}$ are molecules with a polar hydrophilic outside, and an apolar hydrophobic cavity, which provides a guesthost relation to hydrophobic drugs in hydophilic medium which is called "inclusion complex". 9,10
In the past decades, $\mathrm{CD}$ complexation has been extensively applied to enhance the solubility, dissolution, and bioavailability of poorly water-soluble drugs. Therefore, the use of CDs as excipients in different dosage forms has received much attention because upon complex formation advantages such as improved bioavailability, reduction of unwanted side effects, or improved stability have often been claimed. The improvement in absorption rate of drugs administered in solid dosage forms has been related to the increase in both solubility and dissolution rates of the complexes as compared with pure drug. ${ }^{11}$

Some $\mathrm{CD}_{\mathrm{s}}$ contain 9 and more glucose units, but they are not used since it is difficult to obtain them in pure form and they have low complex forming capacity. Those containing less than 6 units of glucose, on the other hand, cannot be prepared for steric reasons. ${ }^{5,12}$ In these complexes, the drug (guest molecule) is entrapped in the cavity of the cyclodextrin (CD) (host). After the complexation, some physical properties of the guest molecule can be changed. For instance, the strength against oxidation, hydrolysis and photochemical reactions can increase, the evaporation speed of volatile substances can significantly decrease. Also when poor soluble drugs are in complex form, the solubility increases. For this reason, in order to enhance the water solubility of poor soluble substances, complex forming with CD's are widely used. ${ }^{13-16}$

The stoichiometries of active material:cyclodextrin complexes and the numerical values of their stability or binding constants are frequently obtained the from the plots of drug solubility against cyclodextrin concentration. This phase-solubility technique was first developed by Higuchi and Connors. ${ }^{17}$ Phase-solubility diagrams are categorized into A and B types. A type phase-solubility profiles are obtained when the solubility of the active material increases with an increase in cyclodextrin concentration. The A-type profile is further subdivided into three profiles. The $A_{L}$ profile indicates that there is a linear increase in solubility as a function of cyclodextrin concentration; 
the $A_{p}$ profile indicates an isotherm, wherein the curve deviates from linearity in a positive manner, suggesting that a ligand or a solubilizer is proportionally more effective at higher concentrations. Conversely, the $A_{N}$ type relation indicates a negative deviation from linearity, which means that the cyclodextrin is proportionally less effective at higher concentration. ${ }^{18}$

In general, the water-soluble $\mathrm{CD}_{\mathrm{s}}$ form A-type phase solubility profiles, whereas the less soluble natural $\mathrm{CD}_{\mathrm{s}}$ generally form B-type profiles. Type B phase-solubility profiles indicate the formation of a complex with naturally occurring $\mathrm{CD}_{s}$, in particular $\beta-\mathrm{CD} .{ }^{9}$ It was found that the addition of polymers can further enhance the drug permeability from aqueous cyclodextrin solutions. ${ }^{19}$

Therefore, it is accepted that water soluble polymers or non-ionic surfactants have significant effects on the formation of the inclusion compounds. ${ }^{20-23}$ The effects of commonly used water soluble polymers, polyethylene glycol 4000 (PEG4000), polyethylene glycol 10000 (PEG10000), polyethylene glycol 20000 (PEG20000), hydroxypropyl methylcellulose (HPMC) and the non-ionic surfactants polysorbate 20 (PS20), polysorbate 40 (PS40), and polysorbate 60 (PS60) on the dissolution rate and solubility of SMZ from the inclusion complexes were also investigated.

In this study, the solid dispersions were prepared by coprecipitation method. ${ }^{24-28}$ The rates of release of the active material from the complexes were determined from dissolution studies using USP XXII paddle method. ${ }^{29}$

\section{Material and methods}

\section{Materials}

Sulfamethoxazole (SMZ) was obtained from Fako Medical (Turkey); in addition, the following were used in the study: $\beta$-cyclodextrin ( $\beta$-CD), hydroxypropyl- $\beta$-cyclodextrin (HP $\beta-C D)$, $\gamma$-cyclodextrin ( $\gamma$-CD) (Fluka), polyethylene glycol 4000 (PEG4000), polyethylene glycol 10000 (PEG10000), polyethylene glycol 20000 (PEG20000), hydroxypropyl methylcellulose (HPMC) polysorbate 20 (PS20), polysorbate 40 (PS40), polysorbate 60 (PS60) (Merck). All other chemicals were analytical grade.

\section{Apparatus}

UV spectrophotometer (Shimadzu UV 1202, Japan), IR spectrophotometer (Jasco FT/IR 420, Japan), differential scanning calorimetry (DSC) (Netzsch Geratebau DSC 204, Germany) and dissolution rate apparatus (Aymes, Turkey) were used.

\section{Phase-solubility studies}

Solubility measurements were performed by the method of Higuchi and solutions containing various concentrations of $\mathrm{CD}_{\mathrm{s}}$ ranging from $2 \times 10^{-3} \mathrm{~mol} \mathrm{~L}^{-1}$ to $15 \times 10^{-3} \mathrm{~mol} \mathrm{~L}^{-1}$ (The solubility of $\beta$-CD is $16.3 \times 10^{-3} \mathrm{~mol} \mathrm{~L}^{-1}$ ) were shaken with $100 \mathrm{mg}$ of SMZ in sealed flasks in a thermostate water bath at a constant temperature of $37^{\circ} \mathrm{C} .{ }^{30}$ After an equilibrium was attained (approximately after three days), aliquots were with drawn and filtered through $0.45 \mu \mathrm{m}$ filters. A portion of the filtrate was then diluted with water and analyzed spectrophotometrically. The solubility constant and the ratio of SMZ:CDs in the complexes were calculated from the phase solubility diagram. ${ }^{18,31}$

The solubilizing effect of water-soluble polymers and non-ionic surfactants was also investigated with phase-solubility studies.
For this purpose, an $100 \mathrm{mg}$ active material was added to aqueous solutions containing $0-15 \%$ of $\mathrm{CD}_{\mathrm{s}}$ and $0.50 \%(\mathrm{w} / \mathrm{v})$ of water soluble polymers (PEG4000, PEG10000, PEG20000, and HPMC) and non-ionic surfactants (PS20, PS40, and PS60). After equilibration, which took at least three days took place at room temperature, the suspensions were filtered through at $0.45 \mu \mathrm{m}$ membrane fitler and analyzed by UV spectrophotometer. The type of complexation and the apparent stability constants $\left(\mathrm{K}_{\mathrm{c}}\right)$ of the drug:cyclodextrin complexes were calculated from the slope of the phase solubility diagrams. ${ }^{21,22,24}$

\section{Solubility studies}

The cationic form of SMZ is the dominating form at $\mathrm{pHs}$ below 1.5 , while the nonionized form dominates between $\mathrm{pH} 2.0$ and 6.0 and the anionic form dominates $\mathrm{pHs}$ above 7.0. Although $\mathrm{CD}_{\mathrm{s}}$ are able to solubilize both nonionized and the anionic forms of the drug they have a small solubilizing effect on the cationic form. After taking these results into consideration the $\mathrm{pHs}$ of the mediums that we are going to be used for solubility and the dissolution studies were adopted to be either $\mathrm{pH} 4.5$ or $\mathrm{pH} 7.0$.

Excess amount of active material (more than it can be dissolved) was added to a closed flask with either $\mathrm{pH} 4.5$ or $\mathrm{pH} 7.0$ and then mixed in a magnetic mixer at $37^{\circ} \mathrm{C}$. Thereafter, the liquid phase was filtered through $0.45 \mu \mathrm{m}$ filters and the amount of active material in the solution was determined. Solubility of the active material was calculated by the point measured during the formation of the equilibrium status.

\section{Preparation of inclusion compounds}

Coprecipitation method given below was used to prepare SMZ's inclusion compounds with $\mathrm{CD}_{\mathrm{s}}$.

\section{Coprecipitation method}

SMZ was dissolved in acetone and added to the aqueous solution of $\mathrm{CD}$ at 1:1 molar ratio. The solvent was allowed to evaporate and then dried under vacuum at $40^{\circ} \mathrm{C}$ for $24 \mathrm{~h}$ and sieved to obtain the optimum particle size. ${ }^{24}$ The solid complexes including solubility enhancer such as water-soluble polymers (PEG4000, PEG10000, PEG20000, HPMC) and non-ionic surfactants (PS20, PS40, PS60) were also prepared with the same method.

\section{Characterization of complexes}

The infrared spectroscopy (IR) of SMZ, $\beta-\mathrm{CD}$ and the inclusion complexes were measured with $\mathrm{KBr}$ discs at $400-4000 \mathrm{~cm}^{-1}$. The amount of active material in each sample were kept constant in each measurement. Differential scanning calorimetry (DSC) was performed using a scanning rate of $10^{\circ} \mathrm{C} / \mathrm{min}$ on a Netzsch Geratebau DSC 204. Samples were heated in a sealed aluminum pans from 50 to $300^{\circ} \mathrm{C}$.

\section{Dissolution rate studies}

Active material release from all the inclusion compounds prepared were performed by using the USP XXII paddle method at 50rpm in $37^{\circ} \mathrm{C}$ for three hours. ${ }^{29}$ It was done in $900 \mathrm{~mL}$ and at $\mathrm{pH} 4.5$ and at pH 7.0 mediums. Samples taken at certain intervals were measured spectrophotometrically.

\section{Results and discussion}

\section{Phase solubility diagram}

Data obtained from the phase solubility studies were used to 
calculate the apparent stability constant $(\mathrm{Kc})$ according to the following equation:

$$
\begin{aligned}
& \mathrm{K}_{\mathrm{c}}=\mathrm{S}_{\mathrm{t}}-\mathrm{S}_{\mathrm{o}} /\left[\mathrm{S}_{\mathrm{o}}\left(\mathrm{L}_{\mathrm{t}}-\left(\mathrm{S}_{\mathrm{t}}+\mathrm{S}_{\mathrm{o}}\right)\right]\right. \\
& \mathrm{S}_{\mathrm{t}}=\text { total concentration of dissolved SMZ } \\
& \mathrm{S}_{\mathrm{o}}=\text { molar solubility of } \mathrm{SMZ} \text { in the presence of cyclodextrin } \\
& \mathrm{L}_{\mathrm{t}}=\text { total cyclodextrin concentration }
\end{aligned}
$$

A $\mathrm{B}_{\mathrm{s}}$ type solubility graph was obtained with $\beta$-CD. The stoichiometric ratio of the complex determined from the descending part of the diagram was found to be 1:1 (SMZ: $\beta-\mathrm{CD}$ ) and the stability constant was found as $122.3 \mathrm{M}^{-1}$ (Figure 1). A type phase-solubility profiles are obtained when the solubility of the active material increases with an increase in cyclodextrin concentration. $A_{L}$ type solubility graph was obtained by chemically modified HP $\beta-\mathrm{CD}$ and the stability constant was too low $\left(39 \mathrm{M}^{-1}\right)$ (Figure 2). No significant increase in solubility of SMZ was observed with $\gamma$-CD and it was concluded that the inclusion complex did not form (Figure 3). However high stability constants of the complexes indicate high stability, very high values complicate the solubility of the drug. Compairing the stability constants, it was concluded that the $\beta-C D$ was the best complex producing $\mathrm{CD}$ for SMZ. Thus in the all remaining studies, only $\beta-\mathrm{CD}$ was used as host molecule. ${ }^{14}$

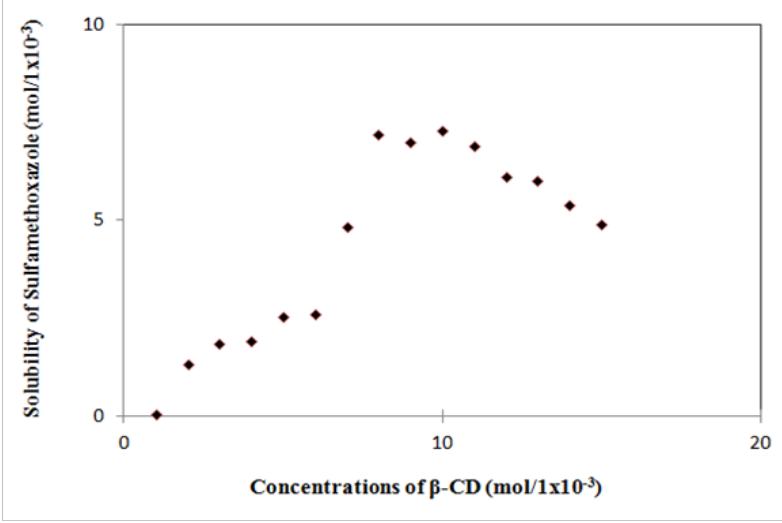

Figure I Phase-solubility diagram of SMZ: $\beta-C D$ system in distilled water.

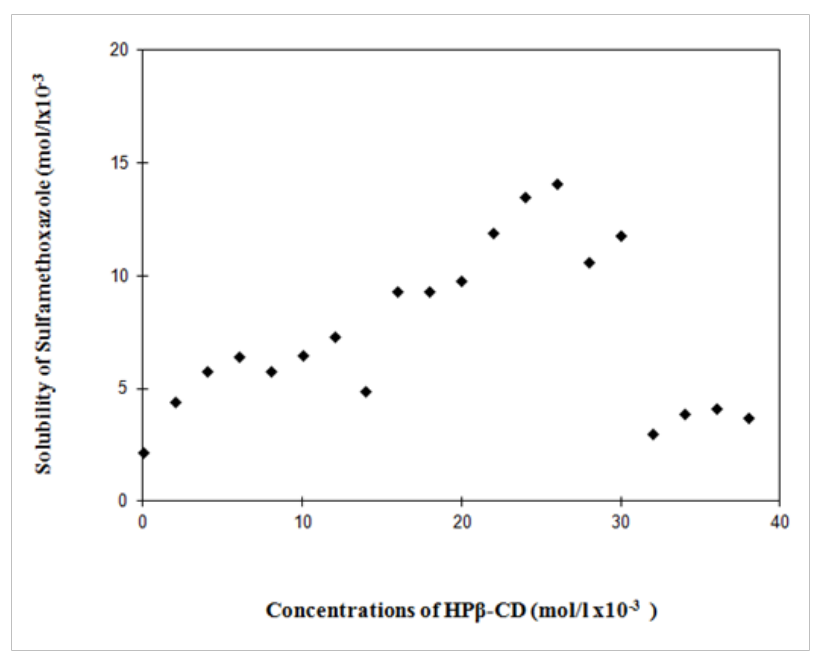

Figure 2 Phase-solubility diagram of SMZ:HPß-CD system in distilled water.

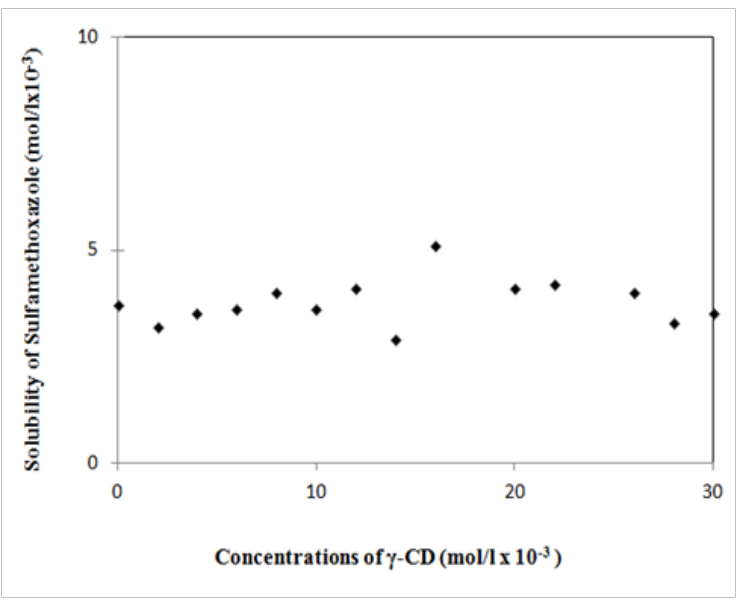

Figure 3 Phase-solubility diagram of SMZ: $\gamma-C D$ system in distilled water.

\section{Solubility studies}

At $\mathrm{pH} 4.5$ (Figure 4 \& Figure 5) and $\mathrm{pH} 7.0$ (Figure 6 \& Figure 7) the solubility of the active material was enhanced in the presence of water soluble polymers (PEG4000, PEG10000, PEG20000) and non-ionic surfactants (PS20, PS40, PS60) (Table 1). No significant increase in the solubility of active material with HPMC was observed. Hence this result was not given in Table 1. As it can be seen in the Figure 5 a higher increase in solubility was observed when PS20 was used rather than PS40 and PS60.

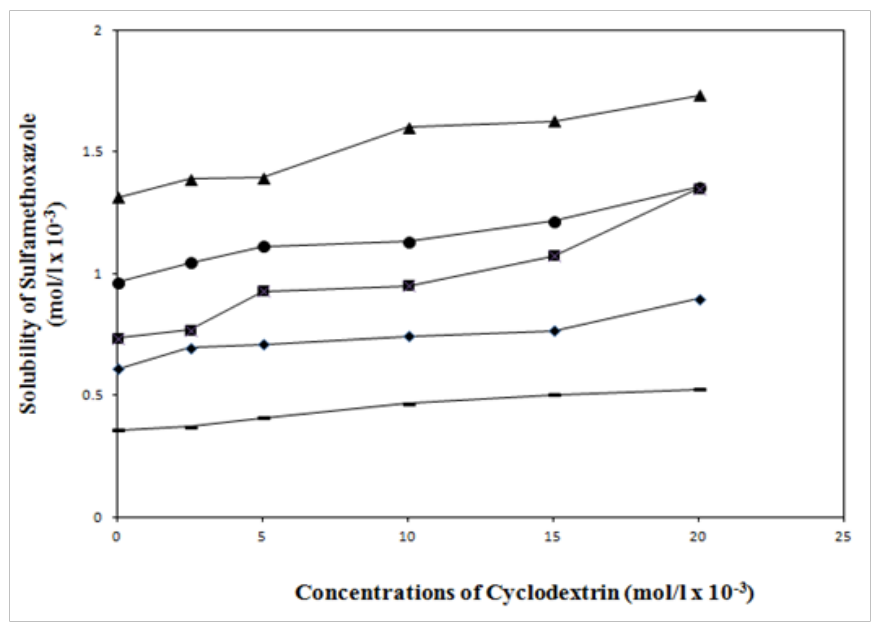

Figure 4 Effect of water soluble polymers (PEG4000, PEG I0000, PEG20000 and $\mathrm{HPMC})(0.5 \% \mathrm{w} / \mathrm{v})$, on the solubility of $\mathrm{SMZ}$ at $\mathrm{pH} 4.5$.

Table I The solubility values of sulfamethoxazole from the inclusioncomplexes at $370 \mathrm{C}$

\begin{tabular}{lll}
\hline Solubility $\left(\mathrm{mg} \mathrm{mL}^{-1}\right)$ & & \\
\hline Formulations & $\mathbf{p H ~ 4 . 5}$ & $\mathbf{p H ~ 7 . 0}$ \\
Sulfamethoxazole & 0.086 & 0.124 \\
Sulfamethoxazole: $\beta-C D(I: I)$ & 0.175 & 0.188 \\
Sulfamethoxazole: $\beta-C D: P E G 20000(\mathrm{I}: \mathrm{I})$ & 0.377 & 0.406 \\
Sulfamethoxazole: $\beta-C D: P S 20(\mathrm{I}: \mathrm{I})$ & 0.349 & 0.386
\end{tabular}




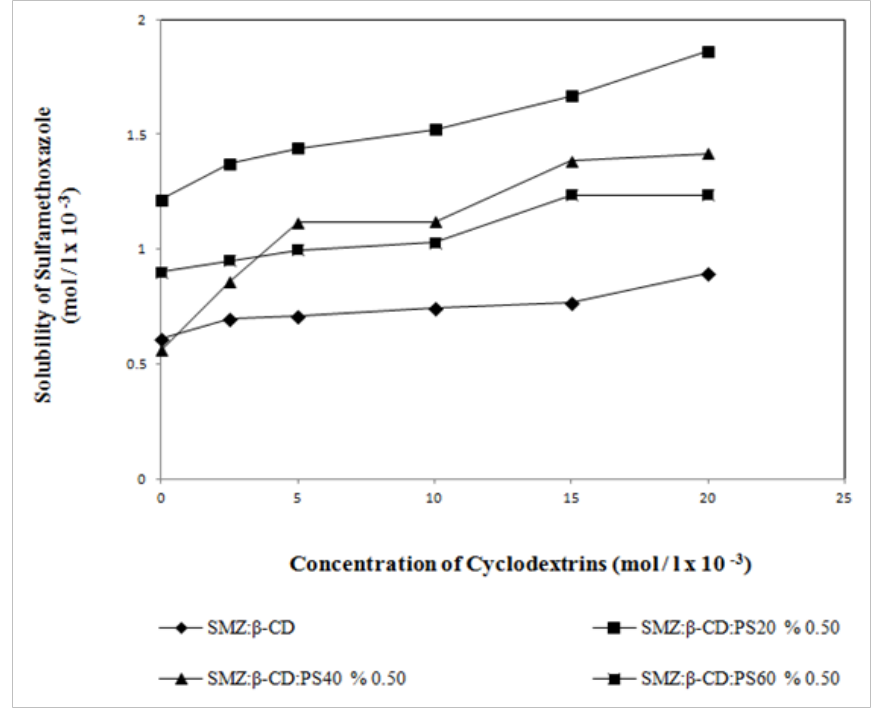

Figure 5 Effect of non-ionic surfactants (PS20, PS40 and PS60) $(0.5 \% \mathrm{w} / \mathrm{v})$, on the solubility of SMZ at $\mathrm{pH} 4.5$.

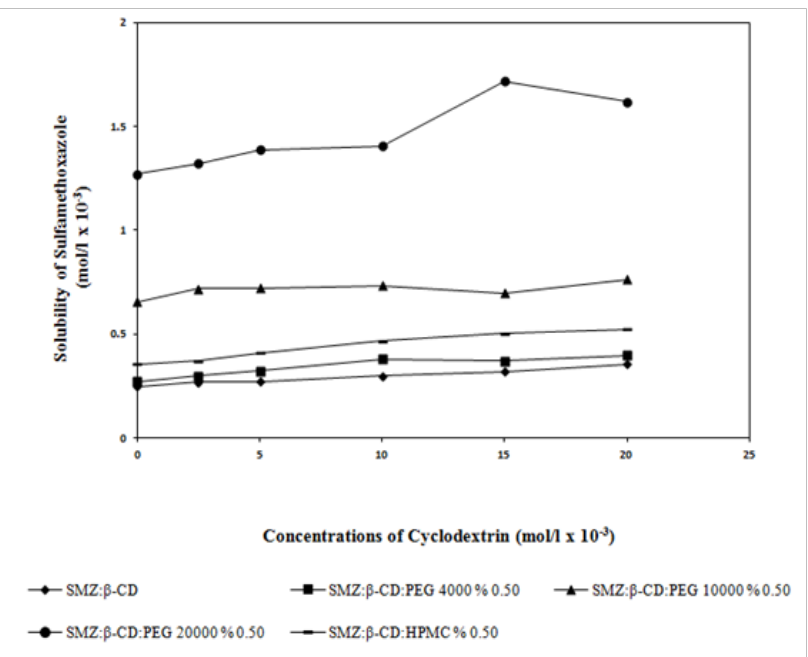

Figure 6 Effect of water soluble polymers (PEG4000, PEG 10000, PEG20000 and HPMC) $(0.5 \% \mathrm{w} / \mathrm{v})$, on the solubility of SMZ at $\mathrm{pH} 7.0$.

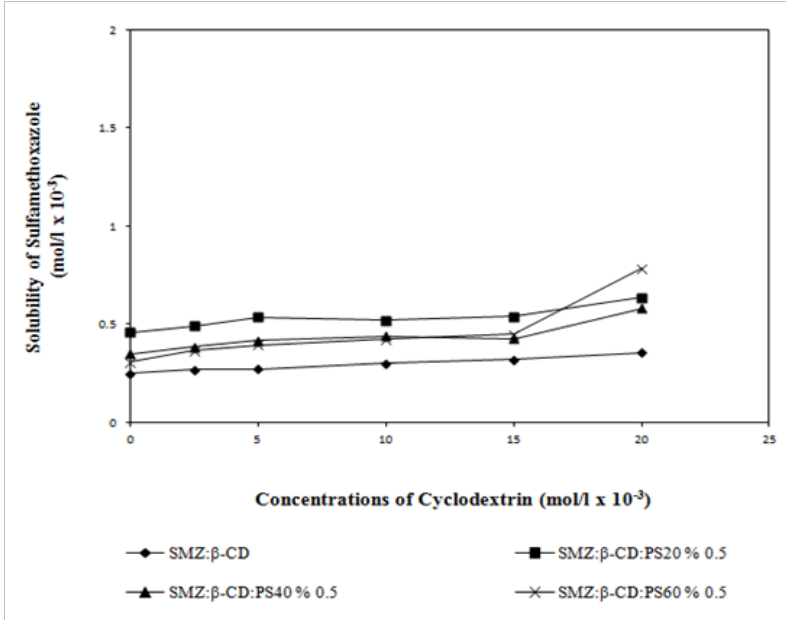

Figure 7 Effect of non-ionic surfactants (PS20, PS40 and PS60) $(0.5 \% \mathrm{w} / \mathrm{v})$ on the solubility of SMZ at $\mathrm{pH} 7.0$.
The solubility of SMZ was significantly increased with the addition of $\beta$-CD from $0.086 \mathrm{mg} \mathrm{mL}^{-1}$ to $0.175 \mathrm{mg} \mathrm{mL}^{-1}$ at $\mathrm{pH} 4.5$ and $0.188 \mathrm{mg}$ $\mathrm{mL}^{-1}$ at $\mathrm{pH} 7.0$ respectively. When PEG4000, PEG10000, PEG20000 were used with SMZ: $\beta-C D$, the solubility increase were greater than the SMZ: $\beta-C D$ alone (Figure $4 \&$ Figure 6). When the effects of polymers and surfactants on the solubility of active material were examined, it was found that the solubility of SMZ was increased by 4.4 times with the formulation including SMZ: $\beta-C D: P E G 20000$ (from $0.086 \mathrm{mg} \mathrm{mL}^{-1}$ to $0.377 \mathrm{mg} \mathrm{mL}^{-1}$ at $\mathrm{pH} 4.5$ and to $0.406 \mathrm{mg} \mathrm{mL}^{-1}$ at $\mathrm{pH}$ 7.0) compared to pure SMZ. The higher solubility $\left(0.377 \mathrm{~g} \mathrm{~mL}^{-1}\right.$ at $\mathrm{pH}$ 4.5 and $0.406 \mathrm{mg} \mathrm{mL}^{-1}$ at $\mathrm{pH} 7.0$ ) were obtained with PEG20000 than the other $\mathrm{PEG}_{\mathrm{s}}$ because of higher hydrophilic nature. The solubility values of SMZ from SMZ: $\beta-C D$ complexes including PEG10000 or PEG4000 were $0.287 \mathrm{mg} \mathrm{mL}^{-1}$ at $\mathrm{pH} 4.5$ and $0.193 \mathrm{mg} \mathrm{mL}^{-1}$ at $\mathrm{pH}$ 7.0 for PEG10000 and $0.241 \mathrm{mg} \mathrm{mL}^{-1}$ at $\mathrm{pH} 4.5$ and $0.100 \mathrm{mg} \mathrm{mL}^{-1}$ at pH 7.0 for PEG4000 respectively. Furthermore besides the solubility increase in both $\mathrm{pH} 7.0$ and $\mathrm{pH} 4.5$, there was found to be a slight difference between two mediums and the higher solubility observed in the $\mathrm{pH} 7.0$ medium was attributed to the presence of SMZ in anionic form. Our results are agreement with the results published by other authors. $^{18}$

\section{The characterization of inclusion compound formation}

Infrared spectrophotometers (IR) and differential scanning calorimetry (DSC) were used to prove the formation of inclusion complexes between the active material and $\beta-\mathrm{CD}$. The characteristic bonds of $\mathrm{SMZ}$ at $1599 \mathrm{~cm}^{-1}\left(-\mathrm{SO}_{2} \mathrm{NH}\right), 1306 \mathrm{~cm}^{-1}\left(-\mathrm{SO}_{2}\right)$ which were observed by IR, seemed to disappear in the inclusion compounds or become modified significantly (Figure 8 ). The observed decreases in the intensities of the characteristic bonds of SMZ may be due to its restriction with in the $\beta$-CD cavity.

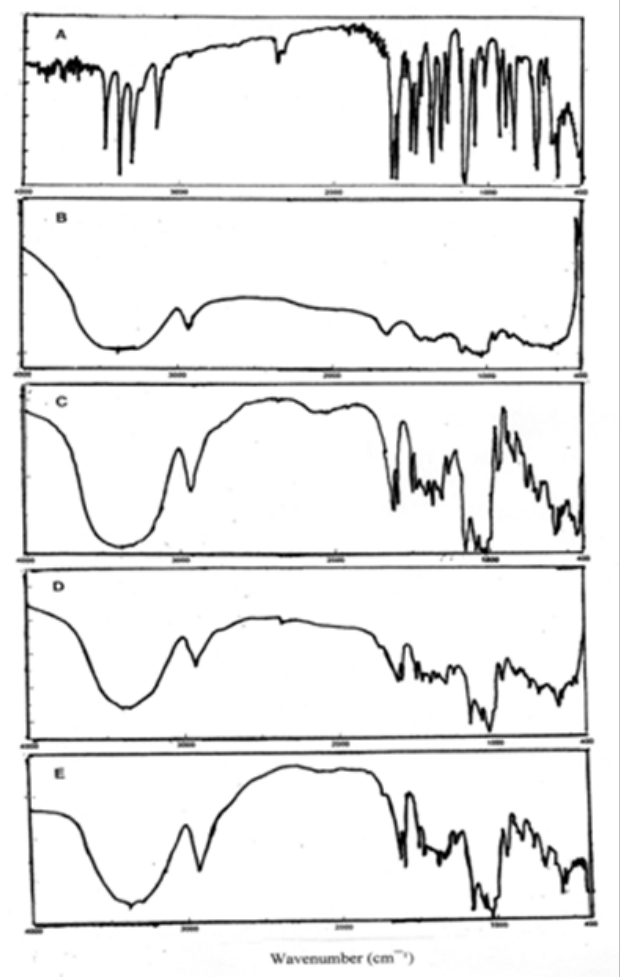

Figure 8 The IR spectra of, A) Sulfamethoxazole, B) $\beta$-Cyclodextrin, C) SMZ: $\beta-C D$ (I:I) coprecipitated inclusion complex, D) SMZ: $\beta-C D: P E G 20000$ $(I: I)$ coprecipitated inclusion complex, E) SMZ: $\beta-C D: P S 20(I: I)$ coprecipitated inclusion complex. 
Figure 9 shows the thermogram of SMZ, $\beta$-CD and the inclusion complexes obtained from DSC measurements. The $\beta$-CD displayed no peaks in the temperature range between $50^{\circ} \mathrm{C}$ and $300^{\circ} \mathrm{C}$ while the SMZ exhibited its characteristic endothermic peak associated with the melting point of the drug around $171^{\circ} \mathrm{C}$. Although, inclusion complexes showed broad peaks, the peak of the SMZ disappeared especially in the presence of PEG20000 and PS20 without distinct phase transition around this temperature. The SMZ: $\beta-C D$ coprepicipitated complex showed a less intense peak. The absence of the peak in DSC curves may be considered as a strong indication of the inclusion formation of the drug into the $\beta-C D$ cavity.

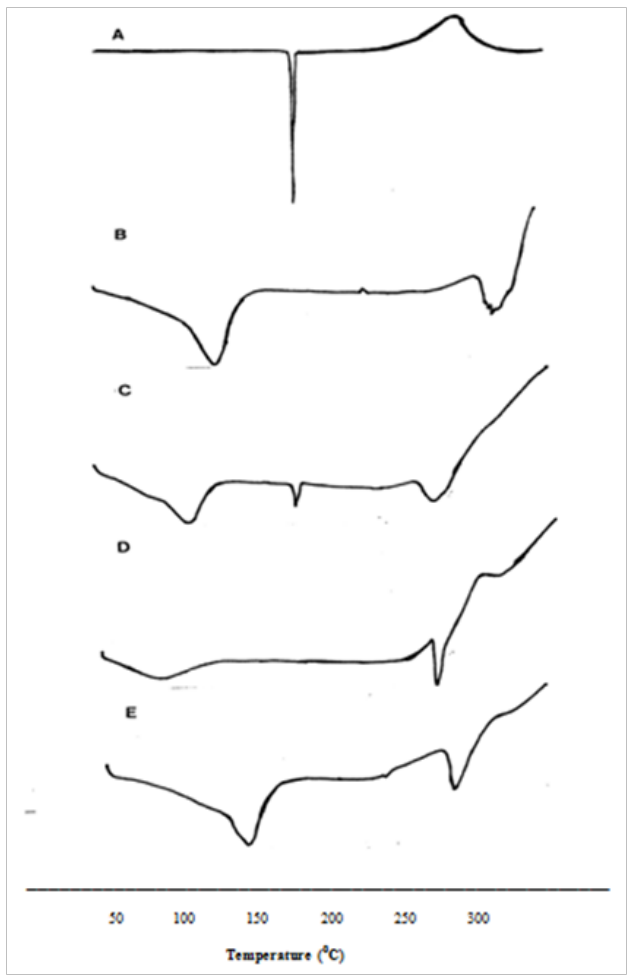

Figure 9 The DSC thermograms of, A) Sulfamethoxazole, B) $\beta$-Cyclodextrin, C) SMZ:B-CD (I:I) coprecipitated inclusion complex, D) SMZ: $\beta-$ CD:PEG20000 (I:I) coprecipitated inclusion complex, E) SMZ: $\beta$-CD:PS20 (I:I) coprecipitated inclusion complex.

\section{Studies on dissolution rate}

The studies conducted at $\mathrm{pH} 4.5$ conditions, in which active material exists in non-ionic form, demonstrated an increase in dissolution rates of complexes when compared to pure active drug rates. On the other hand, adding water soluble polymers (PEG4000, PEG10000, and PEG20000) to the formulation by $0.50 \%(\mathrm{w} / \mathrm{v})$ increased the drug release when compared to the pure drug. $4.7 \%$ of pure SMZ were dissolved within $30 \mathrm{~min}$ whereas the measured values for the formulations including water soluble polymers coded as $\beta$-CD:SMZ, $\beta$-CD:SMZ:PEG4000, $\beta$-CD:SMZ:PEG10000 and $\beta$-CD:SMZ:PEG20000 were $38.0 \%, 22.5 \%, 38.0 \%$ and $41.7 \%$ respectively (Figure 10). It was found that, as the PEG molecule weight increases, so does the active material release. The effect of non-ionic surfactants (PS20, PS40 and PS60) with the concentration of $0.5 \%$ $(\mathrm{w} / \mathrm{v})$ were also examined with dissolution tests. The active material released at the end of the three hours were $39.1 \%, 42.9 \%, 44.1 \%$, and $37.3 \%$ from $\beta$-CD:SMZ, $\beta-C D: S M Z: P S 20, \beta-C D: S M Z: P S 40$, and $\beta-\mathrm{CD}: \mathrm{SMZ}: \mathrm{PS} 60$ respectively. To conclude the presence of these substances was observed to have a somehow significant effect on the active material release (Figure 11).

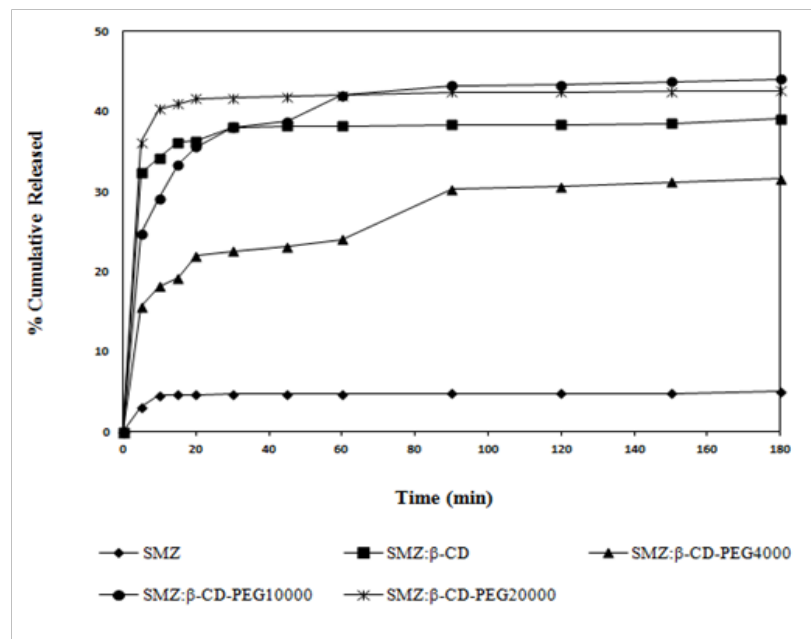

Figure 10 The dissolution profiles of SMZ and its $\beta-C D$ :PEG complexes in $\mathrm{pH} 4.5$.

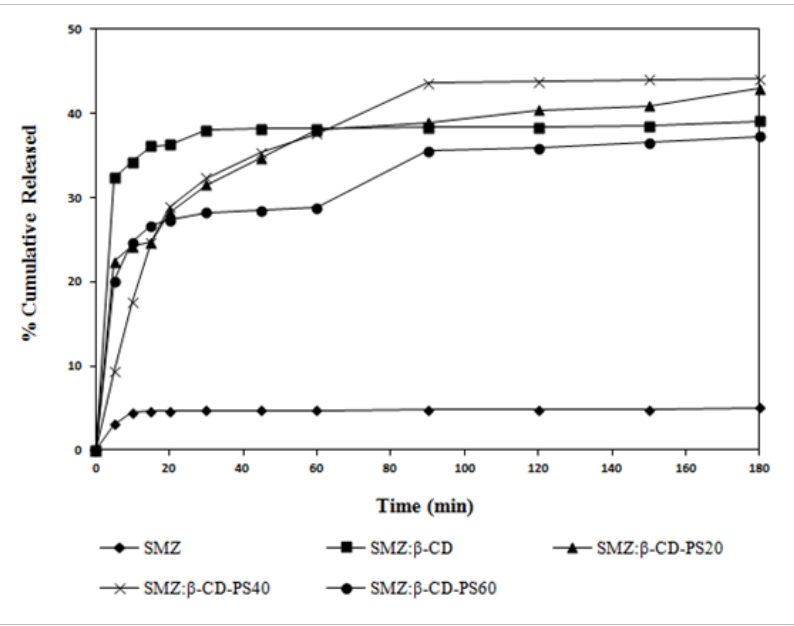

Figure II The dissolution profiles of SMZ and its $\beta-C D$ :PS complexes in $\mathrm{pH}$ 4.5.

A significant increase in drug release was observed in the complexes at $\mathrm{pH} 7.0$ when compared to the pure drug alone. At the end of $30 \mathrm{~min}$, the SMZ release rates were $9.9 \%, 25.5$ and $17.1 \%$ from pure drug alone, $\beta-\mathrm{CD}: \mathrm{SMZ}$ and $\beta-\mathrm{CD}: \mathrm{SMZ}: \mathrm{PEG} 20000$ respectively. The release of active material from the formulations including water soluble polymers (PEG4000, PEG10000 and PEG20000) and nonionic surfactants (PS20, PS40, and PS60) were lower than $20 \%$ within 3 hours. These results point out to the fact that additives had no further effect on the active material release rate at $\mathrm{pH} 7.0$, where the drug substance is in anionic form, when compared to the $\beta-\mathrm{CD}: \mathrm{SMZ}$ complex (Figure 12 \& Figure 13).

It is well known that the therapeutic efficiency of waterinsoluble drugs could be increased by enhancing dissolution, which in turn improves the bioavailability. Our studies also showed that $\beta$-CD:SMZ:PEG20000 coded formulation, which achieved the highest increase in the active material solubility and dissolution rate at $\mathrm{pH} 4.5$ when compared with the pure SMZ, $\beta-\mathrm{CD}: \mathrm{SMZ}$ coded complexes, increased the bioavailability among healthy volunteer participants. ${ }^{28}$ 


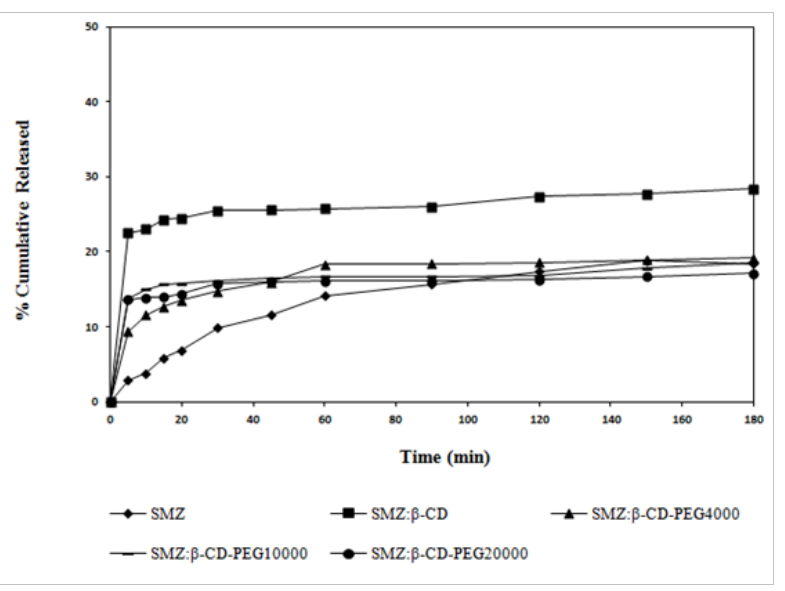

Figure 12 The dissolution profiles of SMZ and its $\beta-C D$ :PEG complexes in $\mathrm{pH}$ 7.0.

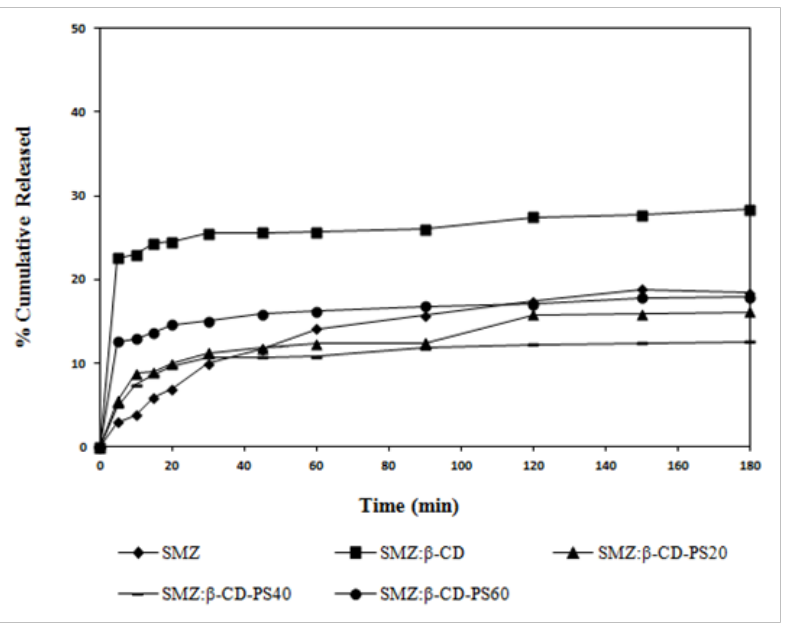

Figure 13 The dissolution profiles of SMZ and its $\beta-C D$ :PS complexes in $\mathrm{pH}$ 7.0

\section{Conclusion}

As a result of this study, it may be concluded that the solubility and the dissolution rate of SMZ was significantly enhanced by the complex formation with $\beta-\mathrm{CD}$. The bioavailability of SMZ has been improved by increasing the solubility and the dissolution rate of SMZ as seen in the previous study.

The water soluble polymers and non-ionic surface active substances added to the solid dispersions increased the solubility and dissolution rate of active material-CD complexes at either $\mathrm{pH} 4.5$ or $\mathrm{pH} 7.0$. Finally, it is thought that, for active substances whose bioavailability is limited by the dissolution rate, absorption and bioavailability may be increased by complexing with cyclodextrins.

\section{Acknowledgements}

None.

\section{Conflict of interest}

No conflict of interest has been declared by the authors.

\section{References}

1. Raja GV, Sekaran CB, Teja DW, et al. Simple spectrophotometric methods for the determination of sulfamethoxazole in pharmaceuticals using folinciocalteau and orcinol as reagents. $J$ of Chemistry. 2009;6(2):357360 .

2. Martindale, the extra pharmacopoeia. $30^{\text {th }}$ ed. In: Reynold JEF, editor. England: Pharmaceutical Press London; 1993: 208.

3. Laura SS, Ribeiro I, Amilcar C, et al. Cyclodextrin Multicomponent Complexation and Controlled Release Delivery Strategies to Optimize the Oral Bioavailability of Vinpocetine. J Pharm Sci. 2007;96(8):20182028.

4. Uekama K. Design and evaluation of cyclodextrin based drug formulation. Chem Pharm Bull. 2004;52(8):900-915.

5. Bekers O, Uijtendaal EV, Beijnen JH, et al. Cyclodextrins in the pharmaceutical field. Drug Dev Ind Pharm. 1991;17(11):1503-1549.

6. Szejtli J. Cyclodextrins in drug formulations: Part 1. Pharm Tech. 1991:36-44.

7. Uekama K, Otagiri M. Cyclodextrins in drug carrier systems. CRC. 1987;3(1):1-40.

8. Gabriel OKL, Yvonne TFT, Kok-Khiang P. Enhancement of norfloxacin solubility via inclusion complexation with $\beta$-cyclodextrin and its derivative hydroxypropyl- $\beta$-cyclodextrin. Asian J Pharm Sci. 2016;11(4):536-546.

9. Brewster ME, Loftsson T. Cyclodextrins as pharmaceutical solubilizers. Adv Drug Del Rev. 2007;59(7):645-666.

10. Jambhekar SS, Breen P. Cyclodextrins in pharmaceutical formulations I: structure and physicochemical properties, formation of complexes, and types of complex. Drug Discov Today. 2016;21(2):356-362.

11. Anroop B, Mahesh A, Bandar E, et al. Enhanced oral bioavailability of acyclovir by inclusion complex using hydroxypropyl- $\beta$-cyclodextrin. Drug Deliv. 2014;21(7):540-547.

12. Fromming VK, Szejtli J. Cyclodextrins in Pharmacy Dordrehcht. Netherlands: Kluwer Academic Publishers; 1994.

13. Szejtli J. Cyclodextrin Technology, Dordrecht. Netherlands: Kluwer Academic Publishers; 1988.

14. Duchene D, Woussidjewe D. The current state of $\beta$-cyclodextrin in pharmaceutics. Acta Pharm Technol. 1990;36(1):1-6.

15. Sinha VR, Anitha R, Ghosh S, et al. Physicochemical characterization and in vitro dissolution behaviour of celecoxib- $\beta$-cyclodextrin inclusion complexes. Acta Pharm. 2007;57(1):47-60.

16. Sharma N, Baldi A. Exploring versatile applications of cyclodextrins: an overview. Drug Delivery. 2016;23(3):729-747.

17. Higuchi T, Connors KA. Phase solubility techniques. Adv Anal Chem Instrum. 1965;4:117-149.

18. Jambhekar SS, Breen P. Cyclodextrins in pharmaceutical formulations II: solubilization, binding constant, and complexation efficiency. Drug Discovery Today. 2016;21(2):363-368.

19. Gaurav T, Ruchi T, Awani KR. Cyclodextrins in delivery systems: Applications. J Pharm Bioalled Sci. 2010;2(2):72-79.

20. Loftsson T, Friðrıksdottır H, Olafsdottır BJ. Solubilization and stabilization of drugs through cyclodextrin complexation. Acta Pharm Nord. 1991;3(4):215-217.

21. Loftsson T, Friðriksdottır H, Thorısdottir S, et al. The effect of hydroxypropyl methylcellulose on the release of dexamethasone from 
aqueous 2-hydroxypropyl- $\beta$-cyclodextrin formulations. Int J Pharm. 1994;104:181-184.

22. Loftsson T, Guðmundsdottir TK, Friðrıksdottır H. The influence of water soluble polymers and $\mathrm{pH}$ on hydoxypropyl- $\beta$-cyclodextrin complexation of drugs. Drug Dev Ind Pharm. 1996;22(5):401-405.

23. Hirlekar RS, Sonawane SN, Kadam VJ. Studies on the effect of watersoluble polymers on drug-cyclodextrin complex stability. AAPS Pharm SciTech. 2009;10(3):858-860.

24. Dhanaraju MD, Kumaran KS, Baskaran T, et al. Enhancement of bioavailability of griseofulvin by its complexation with $\beta$-cyclodextrin. Drug Dev Ind Pharm. 1998;24(6):583-587.

25. Patel SG, Rajput SJ. Enhancement of oral bioavailability of cilostazol by forming its inclusion complexes. AAPS Pharm Sci Tech. 2009;10(2):660669.

26. Elgindy N, Elkhodainy K, Molokhia A, et al. Lyophilized flutamide dispersions with polyols and amino acids: preparation and in vitro evaluation. Drug Dev Ind Pharm. 2011;37(4):446-455.
27. Polonisamy M, Khonam J. Solid dispersion of prednisolone: solid state characterization and improvement of dissolution profile. Drug Dev Ind Pharm. 2011;37(4):373-386.

28. Özdemir N, Erkin J. Enhancement of dissolution rate and bioavailability of sulfamethoxazole by complexation with $\beta$-cyclodextrin. Drug Dev Ind Pharm. 2012;38(3):331-340.

29. The United States Pharmacopeia, (USP XXII). United States Pharmacopeial Convention Inc. 1260, Twinbrook Parkway Rockwille, MD 20852; 1990.

30. Loftsson T, Duchene D. Cyclodextrins and their pharmaceutical applications. Int J Pharm. 2007;329(1-2):1-11.

31. Connors KA, Mollica JA. Theoretical analysis of comparative studies of complex formation solubility, spectral and kinetic techniques. $J$ Pharm Sci. 1966;55(8):772-780. 